\title{
Clinical Characteristics and Side Effects of Multidrug Resistant Tuberculosis Therapy at Top Referral Hospital West Java Indonesia
}

\author{
Rika Nurlaily Rahmawati, ${ }^{1}$ Emmy Hermiyanti Pranggono, ${ }^{2}$ Rovina Ruslami ${ }^{3}$ \\ ${ }^{1}$ Faculty of Medicine Universitas Padjadjaran, ${ }^{2}$ Department of Internal Medicine, Faculty of \\ Medicine Universitas Padjadjaran/Dr. Hasan Sadikin General Hospital Bandung, \\ ${ }^{3}$ Department of Pharmacology and Therapy Faculty of Medicine Universitas Padjadjaran
}

\begin{abstract}
Background: The efficacy of multidrug resistant tuberculosis (MDR TB) therapy is still being questioned. It has lesser quality, longer duration therapy and high toxicity level. This study was conducted to identify clinical characteristics and side effect of MDR TB therapy at Dr. Hasan Sadikin General Hospital, Bandung, Indonesia as the top referral hospital in West Java.

Methods: A retrospective descriptive study was performed to 142 medical records of MDR TB inpatient and outpatient at Dr. Hasan Sadikin General Hospital from January 2012-July 2013. Data was collected on October-November 2013. Data about clinical characteristics and side effects of MDR TB therapy were collected and was analyzed in the form of percentage.

Results: From 142 patients, 96\% had history of tuberculosis therapy. Eighty (56\%) of them had positive acid fast bacilli (AFB) sputum that still remained after 5th month or more with category 2. Seventy (49\%) patients used combination of pyrazinamide, capreomycin, levofloxacin, ethionamide and cycloserine (PzCm-Lfx-Eto-Cs). All patients experienced side effects during therapy and the majority of them (91\%) had gastroenteropathy and rheumatism. Tentamen suicide was detected in one patient.

Conclusions: The MDR TB patients had history of tuberculosis therapy. The majority of patients used combination of Pz-Cm-Lfx-Eto-Cs. All patients experienced side effects during MDR TB therapy. [AMJ.2016;3(4):526-32]
\end{abstract}

Keywords: Characteristics, multidrug resistant tuberculosis therapy, side effect

\section{Introduction}

Multidrug resistant tuberculosis (MDR TB) is defined as tuberculosis infection that caused by resistant microorganism to isoniazid and rifampisin. ${ }^{1}$ It is global emergency case with approximately $3.7 \%$ of new case and $20 \%$ of previous tuberculosis case in 2011., ${ }^{1,2}$ There are $22.2 \%$ of MDR TB cases in developing country. ${ }^{1,2}$ Actually, Indonesia is at the eight rank among 27 burden MDR TB countries. ${ }^{2}$

Therapy of MDR TB has given 56-59\% good prognosis. ${ }^{3,4}$ The most contributing factor is known as man made phenomenon, which included health care facilitators, medications and patients. ${ }^{3,5,6}$ The efficacy of MDR TB therapy, which uses category ${ }^{4}$, is still questionable. The regimen has lesser quality and availability in health care. It is also more expensive and more side effects occur compare to other category. ${ }^{6}$ Longer duration therapy and high toxicity level cause the patients uncompliance to therapy.

The spread of MDR TB cases is still unkown. Updates of research data regarding MDR TB are needed to evaluate the therapy outcomes. Registration of MDR TB patients at Dr. Hasan Sadikin General Hospital Bandung as the top referral hospital in West Jaca Indonesia, just started on January 2012. Therefore, The aim of this study was to identify clinical characteristics and side effects of MDR TB therapy at Dr. Hasan Sadikin General Hospital.

\section{Methods}

A descriptional retrospective study was conducted to medical records of 142 patients with MDR TB, consisted of inpatients and

Correspondence: Rika Nurlaily Rahmawati, Faculty of Medicine, Universitas Padjadjaran, Jalan Raya BandungSumedang Km.21, Jatinangor, Sumedang, Indonesia, Phone: +62 8561574163 Email: rika_nr@ymail.com 
outpatients at Dr. Hasan Sadikin General Hospital, Bandung, Indonesia, on OctoberNovember 2013. Data collection was performed on medical records from January 2012-July 2013 (19 months data) that fullfilled the diagnosis of MDR TB, included sputum culture test and drug susceptibility test (DST). Variable were included in this study, comprised of clinical characteristics and side effects of MDR TB therapy. The clinical characteristics that defined as suspected criteria of MDR TB at early diagnosis were categorized into 8 categories: $^{7}$ 1) sputum that still remained positive of acid fast bacilli (AFB) during previous category 2 tuberculosis (TB) therapy at 5 th month or more; 2 ) sputum that still remained positive of AFB during previous category 2 TB therapy at $3^{\text {rd }}$ month or more; 3 ) sputum that still remained positive of AFB during previous category 1 TB therapy at 5th month or more; 4) sputum that still remained positive of AFB during previous category 1 with additional 1 month TB therapy; 5) history of tuberculosis therapy for $>1$ month in non- directly observed treatment short-course (DOTS) facility, using second line regimen, such as fluoroquinolone and kanamycin; 6) default case; 7) relapse case (category 1 or 2); and 8) close contact to MDR TB patients.

Therapy of MDR TB was defined as anti tuberculosis category 4 regimen therapy of MDR TB patients at Dr. Hasan Sadikin General Hospital. The therapy was categorized into 3 , namely 1) pyrazinamide, kanamycin, levofloxacin, ethionamide, cycloserine (Z-KmLfx-Eto-Cs); 2) pyrazinamide, kanamycin, levofloxacin, ethionamide, cycloserine, ethambutol (Z-Km-Lfx-Eto-Cs-E) and 3) pyrazinamide, levofloxacin. ethionamide, cycloserine, capreomycin (Z-Lfx-Eto-Cs$\mathrm{Cm})$. Side effects of MDR TB therapy defined as side effect that occurred during MDR TB therapy. Data were analyzed in the form of percentage This study had been approved by Health Research Ethics Committee, Faculty of Medicine, Universitas Padjadjaran (number 208) and Dr. Hasan Sadikin General Hospital, Bandung, Indonesia (number 3002).

Table 1 Characteristics of MDR TB Patients

\begin{tabular}{lc}
\multicolumn{1}{c}{ Characteristics of MDR TB Patients } & $\begin{array}{c}\text { Number of Patients } \\
\mathbf{n = 1 4 2}\end{array}$ \\
\hline Gender & $81(57 \%)$ \\
Male & $61(43 \%)$ \\
Female & \\
Age (Years old) & $36(12.565)$ \\
Median (SD) & $15-71$ \\
Range & $11(8 \%)$ \\
Comorbid & $8(5 \%)$ \\
Diabetes mellitus 2 & $1(1 \%)$ \\
Chronic hepatitis & $1(1 \%)$ \\
Lupus and pregnant & $1(1 \%)$ \\
HIV & $110(77 \%)$ \\
No Comorbid & $21(15 \%)$ \\
No Data & \\
Current Condition & $94(66 \%)$ \\
Still in therapy at Dr. Hasan Sadikin General Hospital & $27(19 \%)$ \\
Died & $13(9 \%)$ \\
Drop Out & $7(5 \%)$ \\
Become XDR TB & $1(1 \%)$ \\
Reffered to other Hospital &
\end{tabular}

Notes: HIV=Human Immunodeficiency Virus; SD=Standard Deviation; XDR TB=Extremely Drugs Reistant Tuberculos 
Table 2 Clinical Characteristics of MDR TB Patients

\begin{tabular}{|c|c|}
\hline $\begin{array}{l}\text { Clinical Characteristics } \\
\text { (at Early Diagnosis) }\end{array}$ & $\begin{array}{l}\text { Number of Patients (\%) } \\
n=142\end{array}$ \\
\hline History of Previous TB Therapy & $137(96 \%)$ \\
\hline $\begin{array}{l}\text { Sputum that still remained positive AFB during previous category } 2 \text { TB therapy at } \\
5 \text { th month or more }\end{array}$ & $80(56 \%)$ \\
\hline $\begin{array}{l}\text { Sputum that still remained positive AFB during previous category } 2 \text { TB therapy at } \\
\text { 3rd month or more }\end{array}$ & $19(13 \%)$ \\
\hline $\begin{array}{l}\text { Sputum that still remained positive AFB during previous category } 1 \text { TB therapy at } \\
5 \text { th month or more }\end{array}$ & $15(11 \%)$ \\
\hline Relapse case (category 1 or 2 ) & $14(10 \%)$ \\
\hline Default case & $6(4 \%)$ \\
\hline $\begin{array}{l}\text { Sputum that still remained positive AFB during previous category } 1 \text { with additional } \\
\text { a month TB therapy }\end{array}$ & $2(1 \%)$ \\
\hline $\begin{array}{l}\text { History of TB therapy for }>1 \text { month in non-DOTS facility, using second line regimen, } \\
\text { such as fluoroquinolone and kanamycin. }\end{array}$ & $1(1 \%)$ \\
\hline No History of TB Therapy & $1(1 \%)$ \\
\hline Close contact to MDR TB patients & $1(1 \%)$ \\
\hline No Data & $4(3 \%)$ \\
\hline
\end{tabular}

Notes: TB=Tuberculosis; AFB=Acid Fast Bacilli; MDR TB=Multidrug Resistant Tuberculosis; DOTS=Directly Observed Treatment Short-Course

\section{Results}

Half of patients ( $57 \%$ ) were male, with median age 36. Among 142 patients, 110 (77\%) patients had no comorbid. The majority of patients (66\%) were still in therapy of MDR TB at Dr. Hasan Sadikin General Hospital (Table 1).
Among 142 patients, 96\% of them had previous history of tuberculosis therapy. The majority of them (81\%) still had positive AFB sputum on 5th month or more during previous category 2 tuberculosis therapy, at early diagnosis. Rarely, one (1\%) patients had no history of tuberculosis therapy (Table 2).

Majority patients $(70,49 \%)$ used regimen
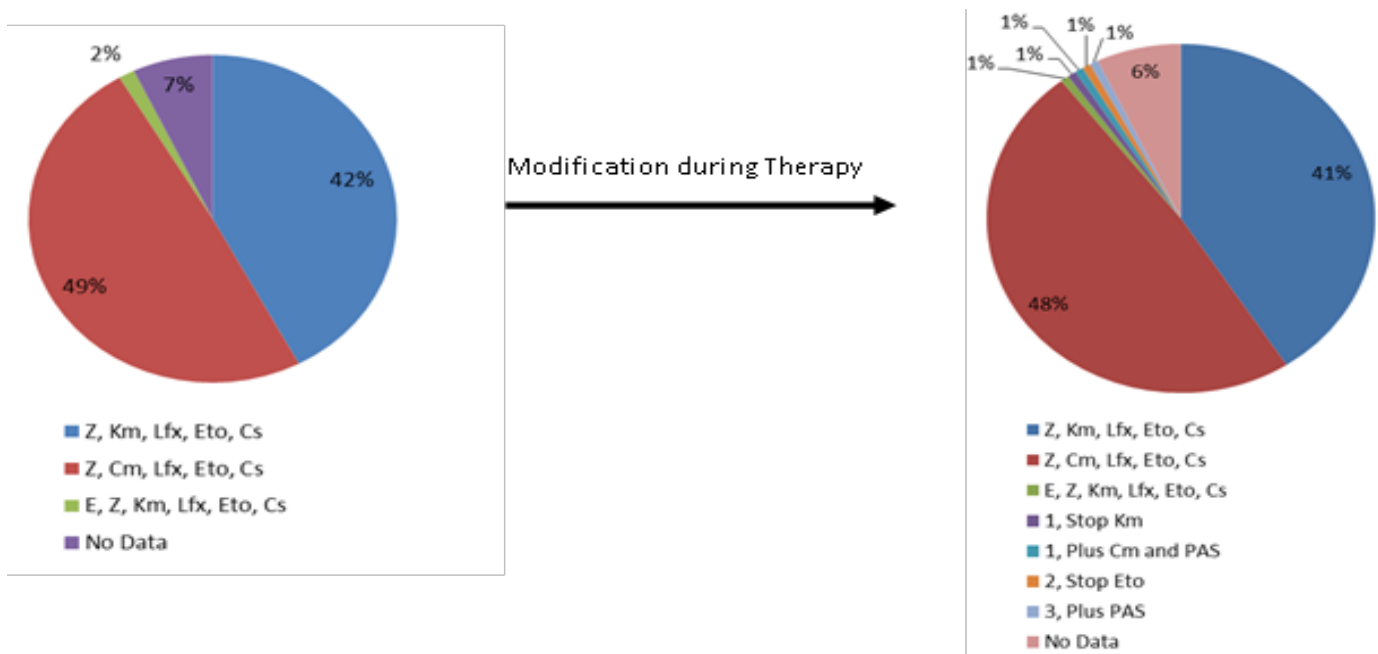

Figure 1 Regimen MDR TB Therapy and Its Modification During Therapy

Notes: $\mathrm{Z}=$ Pyrazinamide; $\mathrm{Km}=$ Kanamycin; Lfx=Lefofloxacin; Eto=Ethionamide; $\mathrm{Cs}=$ Cycloserine; $\mathrm{Cm}=\mathrm{Capreomycin}$; $\mathrm{E}=$ Ethambutol; PAS=P-aminosalycilate acid 
Rika Nurlaily Rahmawati, Emmy Hermiyanti Pranggono, Rovina Ruslami: Clinical Characteristics and Side 529 Effects of Multidrug Resistant Tuberculosis Therapy at Top Referral Hospital West Java Indonesia

Table 3 Most Common Side Effects of MDR TB Therapy

\begin{tabular}{lccc}
\hline \multirow{2}{*}{ Side Effects } & \multicolumn{3}{c}{ Regimen } \\
\cline { 2 - 4 } & $\begin{array}{c}\text { Z Km Lfx Eto Cs } \\
(\mathrm{n}=60)\end{array}$ & $\begin{array}{c}\text { Z Cm Lfx Eto Cs } \\
(\mathrm{n}=70)\end{array}$ & $\begin{array}{c}\text { E Z Km Lfx Eto Cs } \\
\text { (n=3) }\end{array}$ \\
\hline Gastro-enteropathy (n=113) & $47(42 \%)$ & $64(57 \%)$ & $2(2 \%)$ \\
Rheumatism (n=113) & $49(43 \%)$ & $64(57 \%)$ & $2(2 \%)$ \\
Headache (n=113) & $48(42 \%)$ & $63(56 \%)$ & $2(2 \%)$ \\
Hyperuricemia (n=71) & $29(41 \%)$ & $42(59 \%)$ & $0(0 \%)$ \\
Hypokalemia (n=67) & $26(39 \%)$ & $39(58 \%)$ & $2(3 \%)$ \\
Audiometry Abnormality (n=49) & $26(53 \%)$ & $21(43 \%)$ & $2(4 \%)$ \\
Nephrotoxicity & & & \\
Ureum (n=35) & $13(37 \%)$ & $21(60 \%)$ & $1(3 \%)$ \\
Creatinine (n=25) & $11(44 \%)$ & $13(52 \%)$ & $1(4 \%)$ \\
Pain at site of injection (n=25) & $8(32 \%)$ & $16(64 \%)$ & $1(4 \%)$ \\
Psychiatric Status Abnormality (n=26) & $12(46 \%)$ & $14(54 \%)$ & $0(0 \%)$ \\
Tentamen suicide (n=1) & $0(0 \%)$ & $1(1 \%)$ & $0(0 \%)$ \\
Hypothyroidism (n=21) & $9(43 \%)$ & $12(57 \%)$ & $0(0 \%)$ \\
\hline
\end{tabular}

Notes: Z=Pyrazinamide; Km=Kanamycin; Lfx=Lefofloxacin; Eto= Ethionamide; Cs=Cycloserine; Cm=Capreomycin; $\mathrm{E}=$ Ethambutol

therapy of Z-Cm-Lfx-Eto-Cs. From 142 patients, $10(7 \%)$ patients did not have any written data regarding regimen therapy on medical records. Few (4\%) patients had regimen modification (Figure 1).

All patients (100\%) experienced side effects during therapy. The most common side effects were gastroenteropathy, rheumatism and headache in 113 patients (79\%). Among 113 patients that experienced gastroenteropathy and rheumatism, 64 of them used Z-Cm-LfxEto-Cs. One $(1 \%)$ patient had experienced tentamen suicide and it was the most severe side effect of MDR TB therapy (Table 3).

Few patients experienced other side effects of MDR TB therapy. Less than 10\% patients experienced hematologic abnormalities (leucopenia and thrombocytopenia), visual disorder, vertigo, epilepsy, etc (Table 4).

\section{Discussion}

This study discovered that most of MDR TB patients had history of TB therapy, the majority of them still experienced positive AFB sputum on $5^{\text {th }}$ month or more during previous category 2 TB therapy, at early diagnosis. All patients experienced side effects from MDR TB therapy, while the most common side effects were gastroenteropathy, rheumatism and headache. Gastroenteropathy was manifested by nausea, vomit, anorexia, diarrhoea, dan other gastric-enteric disturbance. All patients used combination of pyrazinamide, levofloxacin, ethionamide and cycloserine. In addition to that, $49 \%$ patients used capreomycin and $42 \%$ patients used kanamycin in their combination regimen therapy. It was the first study in Dr. Hasan Sadikin General Hospital, Bandung, Indonesia.

Other common side effects were hyperuricemia, nephrotoxicity, audiometric abnormality, hypothyroidism and drug induced liver intoxination. Manifestations of drug induced liver intoxination were fatigue, nausea, vomit, anorexia, fever and abdominal pain through anamnesis that were written on medical records. Elevation of creatinin and ureum monitored routinely to evaluate side effect of nephrotoxicity. Some patients also experienced psychiatric status abnormality. In this study, a patient experienced tentamen suicide and it was the most severe side effects of therapy. Few patients experienced regimen modification by stopping or adding regimen to their therapy.

In line with this study, a study conducted by Tarek et al. $^{8}$ showed that prevalence of retreatment case was $97.3 \%$, while the remaining were new cases. Based on World Health Organization (WHO) surveillance research data, ${ }^{1} 15 \%$ of patients had history 
Table 2 Clinical Characteristics of MDR TB Patients

\begin{tabular}{|c|c|}
\hline Side Effects & Number of Patients $(n=142)$ \\
\hline Anemia & $17(12 \%)$ \\
\hline Insomnia & $17(12 \%)$ \\
\hline Fatigue & $17(12 \%)$ \\
\hline Lymphocytopenia & $15(11 \%)$ \\
\hline \multicolumn{2}{|l|}{ Drug Induced Liver Injury } \\
\hline SGOT & $13(9 \%)$ \\
\hline SGPT & $2(1 \%)$ \\
\hline Peripheral Neuropathy & $14(10 \%)$ \\
\hline Skin Inflamation Manifestation & $12(8 \%)$ \\
\hline Fever & $11(8 \%)$ \\
\hline Leukocytosis & $7(5 \%)$ \\
\hline Thrombocytosis & $6(4 \%)$ \\
\hline Palpitation & $4(3 \%)$ \\
\hline Visual Disorder & $4(3 \%)$ \\
\hline Dehydration & $4(3 \%)$ \\
\hline Vertigo & $3(2 \%)$ \\
\hline Leukopenia & $2(1 \%)$ \\
\hline Cardiac Rhythm Abnormality & $2(1 \%)$ \\
\hline Thrombocytopenia & $1(1 \%)$ \\
\hline Epilepsy & $1(1 \%)$ \\
\hline Taste and Smell Abnormality & $1(1 \%)$ \\
\hline Polycythemia Sekunder & $1(1 \%)$ \\
\hline Metabolic Acidosis & $1(1 \%)$ \\
\hline
\end{tabular}

Notes: SGOT=Serum Glutamic-Oxaloacetic Transaminase, SGPT=Serum Glutamic-Pyruvic Transaminase

of TB therapy and 3\% of patients were new case. This study showed that $1 \%$ patient had no history TB therapy. Specifically, new case is caused by close contact to MDR TB patients (infected by patients).$^{5}$ According to previous study, there were $36 \%$ of patients still experienced positif AFB sputum during $5^{\text {th }}$ month or more of category 2 TB therapy usage and $32 \%$ of patients experienced relapse case. ${ }^{1}$ It is different from this study whereas fewer $(10 \%)$ of patients were experienced relapse.

These findings were caused by man made phenomenon, which did not follow standardized therapy appropriately. The reason were multifactorial, included patients factor (mostly by uncompliance case, human immunodeficiency virus/ HIV patient), health care facilitators factors (quality of DOTS implementation, access to diagnosing and therapy), and regimen factors (quality of regimen, determination of regimen dose). ${ }^{5,9,10}$

In this study, the side effects of therapy was similar to the previously study by Munawwarah et al. ${ }^{11}$ that $100 \%$ of MDR TB patients had side effects. From surveillance data WHO 2011 research, the most common side effects were nausea/vomit $(32.8 \%)^{1}$ , followed by arthralgia (16.4\%), hearing disturbance $(12 \%)$, headache $(1.7 \%)$ and electrolyte disturbance (11.5\%). ${ }^{1}$

Inappropriate dosage played important role that contributed to side effects of MDR TB patients. ${ }^{1}$ From result findings, rheumatism was manifested with arthralgia, myalgia, gout arthritis through anamnesis and hyperuricemia through laboratory examination. Pyrazinamide has 2 main side effects: drug induced liver intoxication dan gout-like arthralgia (manifested by rheumatism and hyperuricemia). ${ }^{1,12,13}$

Persistent nausea and vomit were caused by ethionamide or p-aminosalicylic acid (PAS), whereas transient nausea \& vomit were caused by pyrazinamide. ${ }^{14,15}$ Gastrointestinal 
disturbance can be caused by levofloxacin. ${ }^{1}$ Meanwhile, pyrazinamide can cause headache, but chronic headache can be probably caused by cycloserine. Headache also can be caused by levofloxacin. ${ }^{1}$

In this study, some patients experienced electrolyte imbalance, specifically hypokalemia. Hypokalemia can be caused by injecting drugs (capreomycin), vomit, diarrhea and other causes. ${ }^{15}$ Patients were usually manifested by fatigue, palpitation, paresthesia, muscle cramp and numbness. Nephrotoxicity can be seen through laboratory examination of ureum and creatinine.$^{15}$ Injecting drugs, such as kanamycin (frequently) and cycloserine, can have direct effect on kidney, that can cause electrolyte imbalance. ${ }^{13}$

Capreomycin and kanamycin can cause auditory abnormality. ${ }^{1,16}$ According to Reviono et $\mathrm{al}^{17}$ that $57.6 \%$ of MDR TB patients experienced hearing disturbance. Out of them, $54.2 \%$ used kanamycin.

Cycloserine can affect psychiatric status of patients, that manifested as depression, anxiety or psychosis (hallucination, delirium). ${ }^{13,14,16}$ High level of TSH can be caused by ethionamide and PAS combination. ${ }^{18,19}$

Few patients had other side effects during MDR TB therapy. Visual disorder can be caused by ethionamide. On the other hand, the most common side effect of ethambutol is neuritis opticus. ${ }^{13}$ Therefore, patients should be monitored by visual acquity test monthly. Rarely, levofloxacin can cause leukopenia and eosinophillia in $<1 \%$ patients. ${ }^{1}$ The PAS also causes thrombocytopenia, agranulocytosis, leukopenia and hemolytic anemia. ${ }^{14}$

Patients had baseline examinations before MDR TB therapy was started. The baseline examinations were laboratorium examination (blood test, urine macroscopic and microscopic test), rontgen, audiometric test, psychiatric status test, thyroid function test, etc. ${ }^{1,14}$ There were also several examinations for follow up the patients during MDR TB therapy routinely. Those examinations were rontgen, laboratorium examination (blood and urine), thyroid function test, audiometric test, psychiatric status test, etc. ${ }^{1,6,8}$ By those baseline examinations and follow up examinations routinely, physicians can evaluate condition of patients, whether side effects and its management or regimen modification during therapy. ${ }^{14}$

The therapy modifications depend on severity of patients's condition. It can be caused by some condition, such as nontolerated side effects or new drug resistant. ${ }^{1}$
Usage of kanamycin can be stopped if the side effects are worsened, for example severe ototoxicity or nephrotoxicity. Ototoxicity can be observed monthly by follow up and audiometric test, while nephrotoxicity can be monitored by creatinine level. Kanamycin also can cause vertigo. Usage of ethionamide can be stopped if the side effects are worsened, for example severe nausea and vomit, that leads to dehydration. Monitoring electrolyte is needed in this case. Capreomycin is indicated, if there is no improvement (resistant) to kanamycin, based on DST result. ${ }^{20}$ The PAS has welltolerated and no cross resistance.

Data about baseline and clinical characteristics, regimen and mainly side effects of MDR TB patients were still not completely written in medical records. This condition was the limitation of this study.

In conclusion, most of MDR TB patients in Dr. Hasan Sadikin General Hospital had previous history of tuberculosis therapy. The majority of them still experienced positive AFB sputum on $5^{\text {th }}$ month or more during previous category 2 tuberculosis therapy, at early diagnosis. The majority of patients used combination of pyrazinamide, capreomycin, levofloxacin, ethionamide and cycloserine. The majority of them had gastroenteropathy and rheumatism. All patients experienced side effects during MDR TB therapy. The most common side effects were gastroenteropathy, rheumatism and headache. The most severe side effect was tentamen suicide. Few patients had regimen modification during therapy depends on their condition for better therapy outcomes.

In this secondary data based survey, complete written findings of status patients during therapy by health care facilitators were needed to evaluate patient condition. By that process, updates of research data regarding MDR TB can be achived to monitor the effectivity of therapy. Further study needed to be conducted for evaluation of MDR TB patients, either by primary and secondary data collection.

\section{References}

1. Falzon D, Jaramillo E, Schünemann HJ, Arentz M, Bauer M, Bayona J, et al. WHO guidelines for the programmatic management of drug-resistant tuberculosis: 2011 update. Eur Respir J. 2011;38(3):516-28.

2. WHO. Global tuberculosis report. 
Switzerland: World Health Organization; 2012.

3. Munir SM, Nawas A, Soetoyo DK. Pengamatan pasien tuberkulosis paru dengan multidrug resistant (TB-MDR) di Poliklinik Paru RSUP Persahabatan. J Respir Indo. 2010;30(2):92-104.

4. Eker B, Ortmann J, Migliori GB, Sotgiu G, Muetterlein R, Centis R, et al. Multidrug-and extensively drug-resistant tuberculosis, Germany. Emerg Infect Dis. 2008;14(11):1700-6.

5. Aditama T, Kamso S, Basri C, Surya A. Pedoman nasional penanggulangan tuberkulosis. 2nd ed. Jakarta: Departemen Kesehatan RI. 2007. p. 1-33.

6. Burhan E. Peran ISTC dalam Pencegahan MDR. Jurnal Tuberkulosis Indonesia. 2010;7:12-5.

7. Depkes RI. Petunjuk teknis penatalaksanaan pasien TB-MDR. Jakarta: Departemen Kesehatan RI. 2009.

8. Safwat TM, Elmasry AA, Mohamed AKM. Prevalence of multidrug resistant tuberculosis in Abbassia Chest Hospital from July 2006 to December 2009. EJB. 2011:5(2):124-30.

9. Novizar D, Nawas A, Burhan E. Identifikasi faktor resiko tuberkulosis multidrugresistant (MDR-TB). Maj Kedokt Indon. 2010;60(12):537.

10. Van Deun A, Salim MA, Das AP, Bastian I, Portaels F. Results of a standardised regimen for multidrug-resistant tuberculosis in Bangladesh. Int J Tuberc Lung Dis. 2004;8(5):560-7.

11. Munawwarah R, Leida I, Wahiduddin. Gambaran faktor resiko pengobatan TBMDR RS Labuang Baji Kota Makassar Tahun 2013 [thesis]. Makassar: Hasanuddin University. 2013.

12. Younossian AB, Rochat T, Ketterer JP, Wacker J, Janssens JP. High hepatotoxicity of pyrazinamide and ethambutol for treatment of latent tuberculosis. Eur Respir J. 2005;26(3):462-4.

13. Torun T, Gungor G, Ozmen I, Bolukbasi Y, Maden E, Bicakci B, et al. Side effects associated with the treatment of multidrugresistant tuberculosis. Int J Tuberc Lung Dis. 2005;9(12):1373-7.

14. Shin SS, Pasechnikov AD, Gelmanova IY, Peremitin GG, Strelis AK, Mishustin S, et al. Adverse reactions among patients being treated for MDR-TB in Tomsk, Russia. Int J Tuberc Lung Dis. 2007;11(12):1314-20.

15. Shin S, Furin J, Alcántara F, Hyson A, Joseph K, Sánchez E, et al. Hypokalemia among patients receiving treatment for multidrug-resistant tuberculosis. Chest. 2004;125(3):974-80.

16. Chan ED, Laurel V, Strand MJ, Chan JF, Huynh M-LN, Goble M, et al. Treatment and outcome analysis of 205 patients with multidrug-resistant tuberculosis. Am J Respir Crit Care Med. 2004;169(10):1103-9.

17. Reviono, Widayanto, Harsini, Aphridasari J, Sutanto YS. Steptomisin dan insidensi penurunan pendengaran pada pasien multidrug resistant Tuberculosis di Rumah Sakit Dr. Moewardi. J Respir Indo. 2013;33(3):167-72.

18. Satti H, Mafukidze A, Jooste PL, McLaughlin MM, Farmer PE, Seung KJ. High rate of hypothyroidism among patients treated for multidrug-resistant tuberculosis in Lesotho. Int J Tuberc Lung Dis. 2012;16(4):468-72.

19. Muchtar A. Farmakologi obat antituberkulosis (OAT) sekunder. Jurnal Tuberkulosis Indonesia. 2006;3(2):23-9.

20. Njaramba P, Naidoo S. Managing multidrugresistant tuberculosis in hospitalised patients: a review of treatment outcomes. South Afr J Epidemiol Infect. 2007;22(2,3):39-44. 